\title{
Numerical and experimental investigation on the thermal behaviour of the building integrating occupant thermal comfort
}

\author{
Abed Al Waheed Hawila ${ }^{1, *}$, Abdelatif Merabtine ${ }^{1,2}$, and Nadège Troussier ${ }^{1}$ \\ ${ }^{1}$ ICD-CREIDD, STMR CNRS 6281, University of Technology of Troyes, 12 rue Marie Curie, CS 42060, 10004, Troyes Cedex, France \\ ${ }^{2}$ EPF School of Engineering, 2 rue Fernand Sastre, 10430, Rosières-Prés-Troyes, France
}

\begin{abstract}
Simulation tools are widely used to model buildings in order to predict their indoor air quality and energy consumption. The prediction capability of the model is an influential factor in determining the ability of the building to be energy efficient and thermally comfortable. Thus, the validation of the developed models is crucial. In this context, this paper presents a numerical model developed using an object-oriented modelling tool based on the Modelica approach and a case study validation of this model. Then the thermal behaviour of the building and the occupants' thermal comfort in the considered case study are investigated. The objective is to validate the developed model firstly by comparing predicted results with measured data regarding room temperature and relative humidity, and secondly by comparing the calculated thermal comfort indices (PMV and PPD) based on predicted results and measured data. The results show good agreement between simulations and experiments, with a maximum error in room temperature and relative humidity of $1.7{ }^{\circ} \mathrm{C}$ and $4.5 \%$, respectively, and only $1 \%$ and $1.5 \%$ difference between averaged values of PMV and PPD, respectively.
\end{abstract}

\section{NOMENCLATURE}

$\begin{array}{ll}\text { M } & \text { Metabolic rate }\left(\mathrm{W} . \mathrm{m}^{-2}\right) \\ \text { PMV } & \text { Predicted Mean Vote } \\ \text { PPD } & \text { Percentage of Persons Dissatisfied (\%) } \\ \text { RH } & \text { Relative Humidity }(\%) \\ \mathrm{W} & \text { External work }\left(\mathrm{W} \cdot \mathrm{m}^{-2}\right) \\ I_{c l} & \text { Thermal resistance of clothing }\left(\mathrm{m}^{2} \cdot \mathrm{K} . \mathrm{W}^{-1}\right) \\ f_{c l} & \text { The ratio of surface area of the body with clothes } \\ & \text { to the surface area of the body without clothes } \\ T_{a} & \text { Air temperature }(\mathrm{K}) \\ T_{r} & \text { Mean radiant temperature }(\mathrm{K}) \\ V_{a r} & \text { Relative air velocity }(\mathrm{m} / \mathrm{s}) \\ P_{a} & \text { Water vapour partial pressure }(\mathrm{Pa}) \\ h_{c} & \text { Convective heat transfer coefficient }\left(\mathrm{W} \cdot \mathrm{m}^{-2} \cdot \mathrm{K}^{-1}\right) \\ T_{c l} & \text { Clothing surface temperature }(\mathrm{K})\end{array}$

\section{Introduction}

The building sector in France is one of the largest energy end-use sectors, accounting for $44.5 \%$ of the total energy consumption larger than both transportation (32\%) and industry (20.7\%) [1]. In the European Union, buildings account for about $40 \%$ of the total energy consumption and contribute to $36 \%$ of the $\mathrm{CO} 2$ emissions [2]. This concern has led the Energy Performance of Buildings Directive (EBPD) to state that the energy efficiency of existing buildings must be improved, and all new buildings must be close to zero energy in 2020 [2]. However, designers have to keep in mind that the primary objective of the buildings is to provide a comfortable environment for their occupants. Thus, the designing for energy-efficient buildings must be based on thermal comfort standards.

Thermal comfort is defined as "the condition of the mind in which satisfaction is expressed with the thermal environment" [3]. Over the years, the analysis of indoor air quality and the design of HVAC systems have led to set up a large number of thermal comfort indices, among all of them, Fanger's [4] Predicted Mean Vote (PMV) and Percentage of Persons Dissatisfied (PPD) are the most applicable indices that can be used to evaluate the thermal comfort within an air-conditioned space and to quantify its value.

Fanger [4] developed an empirical equation, based on the Fanger comfort equation for human body heat exchange [4], which makes it possible to calculate the PMV as a function of two occupants related parameters described as clothing insulation and metabolic rate and four environmental parameters noted as air temperature, mean radiant temperature (MRT), relative humidity, and air velocity. PMV index has been adopted by various national and international standards, such as ISO 7730 [5], ASHRAE 55 [6], and CEN CR 1752 [7].

On the other hand, simulation tools are widely used to model buildings in order to predict their indoor air quality and energy consumption. These expectations have to be reliable. Essentially, the simulation results must reflect the ambiguity effects associated with the design parameters, construction quality, building uses and climatic conditions. Hence, building models need to be validated. In this context, numerous research works have been performed to validate models developed using

\footnotetext{
* Corresponding author: abed_al_waheed.hawila@utt.fr
} 
building energy simulation tools [8,9]. For instance, Bontemps and Mora [10] developed their model using Modelica and validated it by comparing the predicted results with measured data regarding room temperature and heating power. However, to our best knowledge, no study in the literature uses the thermal comfort indices to validate a developed numerical model.

In this context, this paper presents a numerical model developed using an object-oriented modelling tool based on the Modelica approach, and a case study validation of this model. Then the thermal behaviour and occupants' thermal comfort in the case study are investigated. In this way, a brief description of the used thermal comfort indices is presented in the next section. The case study and the building description are then described in section 3. Afterward, the numerical model combining the room envelope, HVAC systems, and Fanger model to calculate the thermal comfort indices is developed and presented in section 4. Indeed, the developed model needs to be validated. For this, simulation results are compared with the measured data regarding room temperature, relative humidity, and thermal comfort indices. The results of the validation process and its corresponding discussion are presented in section 5. Finally, the conclusion of the work is demonstrated in section 6 .

\section{Thermal comfort indices}

PMV is the index that predicts the mean thermal sensation vote on a standard scale for a large group of persons for any given combination of the thermal environmental variables and activity and clothing levels [11]. It is an index that describes the level of thermal comfort in an environment on a subjective seven value scale from cold to hot as shown in Table 1. It is recommended to maintain the PMV at 0 with a tolerance of 0.5 in order to ensure a comfortable indoor climate [5]. This recommendation leads to a maximum of $10 \%$ dissatisfaction in the indoor environment [5]. The mathematical formulation used to calculate the PMV index is as follows:

$$
\begin{gathered}
P M V=\left(0.303 \mathrm{e}^{-0.036 M}+0.028\right)\{(M-W)- \\
3.05 \times 10^{-3}\left[5733-6.99(M-W)-P_{a}\right]-0.42[(M- \\
W)-58.15]-1.7 \times 10^{-5} M\left(5867-P_{a}\right)-0.0014 M \\
\left.\left(34-T_{a}\right)-3.96 \times 10^{-8} f_{c l}\left(T_{c l}{ }^{4}-T_{r}^{4}\right)-f_{c l} h_{c}\left(T_{c l}-T_{a}\right)\right\} \\
T_{c l}=35.7-0.028(M-W)-0.155 I_{c l}\left[3.96 \times 10^{-8} f_{c l}\right. \\
\left.\left(T_{c l}{ }^{4}-T_{r}{ }^{4}\right)+f_{c l} h_{c}\left(T_{c l}-T_{a}\right)\right] \\
h_{c}=\max \left[2.38\left(T_{c l}-T_{a}\right)^{0.25}, 12.1\left(V_{a r}\right)^{0.5}\right] \\
f_{c l}=1.00+0.2 I_{c l} \text { if } I_{c l} \leq 0.5 \mathrm{clo} \\
f_{c l}=1.05+0.1 I_{c l} \text { if } I_{c l}>0.5 \mathrm{clo}
\end{gathered}
$$

PPD model computes the percentage of persons that are dissatisfied within their surrounding thermal environment. PPD is computed from PMV value using the following relation:

$$
P P D=1-0.95 \exp \left(-0.03353 P M V^{4}-0.2179 P M V^{2}\right)
$$

It is worth noting that the mathematical model of the PPD assumes that there is always at least $5 \%$ of individuals in a situation of discomfort.

Table 1. The qualitative and quantitative statements of human

\begin{tabular}{ccccccc}
\multicolumn{8}{c}{ thermal sense. } \\
\hline-3 & -2 & -1 & 0 & +1 & +2 & +3 \\
Cold & Cool & $\begin{array}{c}\text { Slightly } \\
\text { Cool }\end{array}$ & Neutral & $\begin{array}{c}\text { Slightly } \\
\text { warm }\end{array}$ & Warm & Hot \\
\hline
\end{tabular}

\section{Experimental study}

\subsection{Case study}

The building considered in this study was inaugurated in March 2014 and located in Troyes, France. The building has a surface area of $3000 \mathrm{~m}^{2}$ spread over three levels as well as an innovative architecture and high environmental quality valorising renewable energies. It is designed to be a "low energy consumption" building and to meet the requirements of the 2012 Thermal Regulation [12]. It integrates many technologies to reduce its energy consumption and favour the comfort of its users. The building is equipped with a dual-flow ventilation system, which benefits from intelligent regulation thanks to an array of sensors in the various rooms to indicate the values of temperature and the rate of carbon dioxide. Nevertheless, despite these facilities and all the studies carried out, there are gaps between expectations and reality. In the south-east part of the ground floor of the building, a room called "Foyer" (Figure 1), a confidential place of life in which students meet every day to eat, rest, do activities, etc. the students claim that there is a significant difference in temperature with other parts of the building and they are experiencing thermal discomfort. Table 2 reports a brief description of the Foyer.

\subsection{Measurement}

In order to study students' thermal comfort in the Foyer, a multifunctional sensor (Figure 2) developed by IES (Institut d'Electronique et des Systèmes) was used to monitor the environmental parameters of the Foyer and to calculate and visualize in real-time the indices of thermal comfort (PMV and PPD) [13]. The sensor measures the room and radiative temperature, air velocity, relative humidity, and the rate of carbon dioxide. Then it transmits the data using Wi-Fi to a work station. During data collection, the measurements made by the sensor are recorded as data frames in a text file. These data frames are directly used to plot the evolution of the different physical quantities during the series of 
measurements. Five measuring cycles were carried out from Wednesday $12^{\text {th }}$ until Friday $14^{\text {th }}$ November. In this study, we only present one cycle of measurements regarding room temperature and relative humidity because it was carried out for a significant duration of time (24 hours). While the PMV and PPD for all studied cycles are presented.

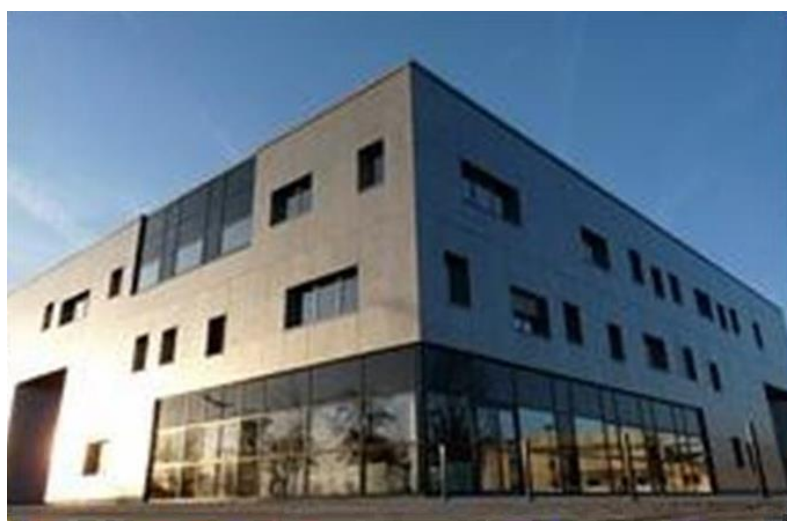

(a)

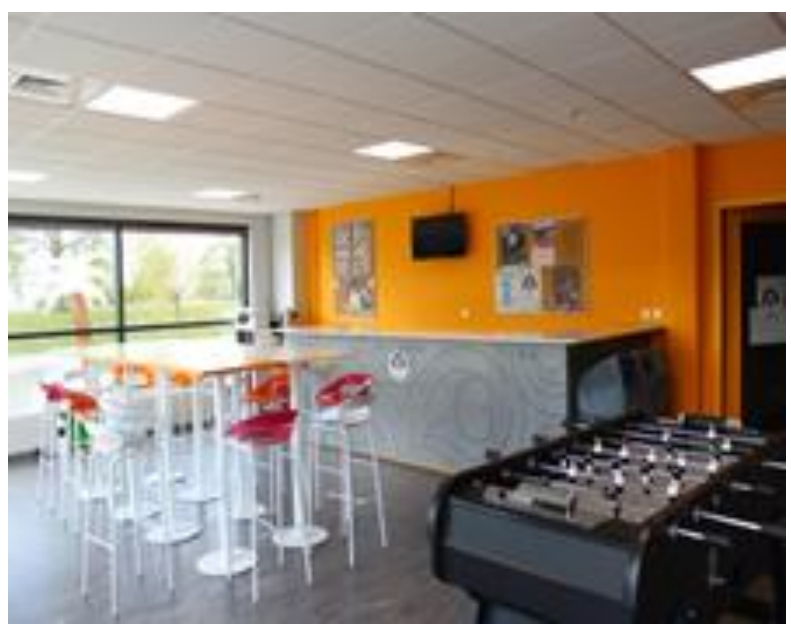

(b)

Figure 1. The Foyer: (a) south-east view; (b) inside view.

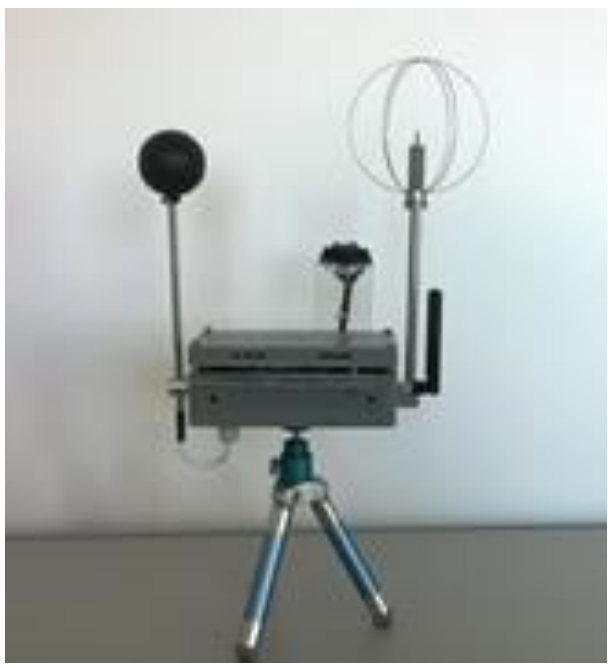

Figure 2. The multifunctional sensor [13].
Table 2. Brief description of the Foyer's characteristics.

\begin{tabular}{ll}
\hline Location & Troyes city, France \\
\hline Net area & $58.0 \mathrm{~m}$ \\
Dimensions & $\mathrm{L} \times 1: 37.16 \mathrm{~m}$ x $37.16 \mathrm{~m} ;$ \\
Ceiling height & $2.54 \mathrm{~m}$ \\
Orientation & south- and east-oriented glass façades \\
Roof & U-value $=0.4 \mathrm{~W} \cdot \mathrm{m}^{-} . \mathrm{K}^{-1}$ \\
Internal wall & $\mathrm{U}$-value $=4.1 \mathrm{~W} \cdot \mathrm{m}^{-} . \mathrm{K}^{-1}$ \\
Glass façade & $\mathrm{U}=2.7 \mathrm{~W} \cdot \mathrm{m}^{-} \cdot \mathrm{K}^{-1}$ and $\mathrm{SHGC}=0.6$ \\
Internal gains & $5.5 \mathrm{~W} \cdot \mathrm{m}^{-}$ \\
Operating hours & Monday to Friday $08: 00$ to $20: 00 ;$ \\
\hline & \\
HVAC system & \\
\hline (a)Ventilation & Supply air temperature $20^{\circ} \mathrm{C}$, heat recovery \\
& system efficiency $66 \%$ \\
& Air volume flow rate $208 \mathrm{~m}^{3} \cdot \mathrm{h}^{-1}$ \\
(b)Radiators & Supply water temperature function of \\
& outdoor temperature \\
& Water volume flow rate $0.1 \mathrm{~m}^{3} \cdot \mathrm{h}^{-1}$ \\
\hline
\end{tabular}

\section{Modelling with Dymola}

The numerical model was developed using the Dymola ${ }^{\circledR}$ graphical interface. Figure 3(a) describes the interaction between sub-models and Figure 3(b) shows the Dymola ${ }^{\circledR}$ model. Both Modelica Buildings Library [14-16] and Modelica Standard Library have been used.

Room model: MixedAir model of the Rooms package [14] is the main component of the model; it is used to illustrate a single room with an unlimited number of opaque constructions. It implies that the air inside the room is completely mixed and simulates all the heat transfer processes (convection, conduction, solar radiation and infrared radiation) within the room and through the building envelope. Hence, it takes the heat transfer through walls, ceiling, floor, and windows into consideration. The properties of the interior walls, ceiling, and floor are represented using the components OpaqueConstructions and Singlelayer of the HeatTransfer package. And the thermal properties of exterior walls (double glazed walls) were presented using the component Glazingsystems from the HeatTransfer package. The glazed walls in the Foyer have no overhangs and side fins; however, they are equipped with roller blinds.

Weather data: The ReaderTMY3 model of the BoundaryConditions package [15] was used to represent the outdoor weather conditions. In this model, the atmospheric pressure is a set parameter, while other parameters are obtained from the TMY3 file. Another possibility is to use a constant value or an input connector for some parameters (dry bulb temperature, relative humidity, infrared horizontal radiation). In our case, we used the Dayschedule model to define the outside temperature at the time of experimentation, and we fed it to the weather file using an input connector. Conversely, for the solar radiations, we used the data from the weather file, because we don't have any measured values for the day of experimentation. 


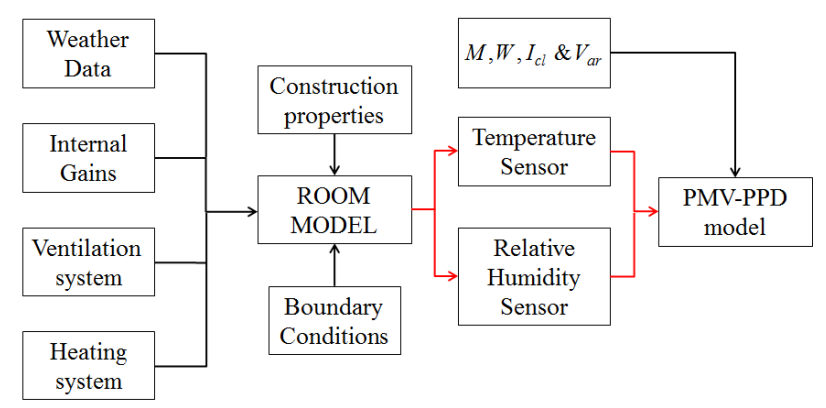

(a)

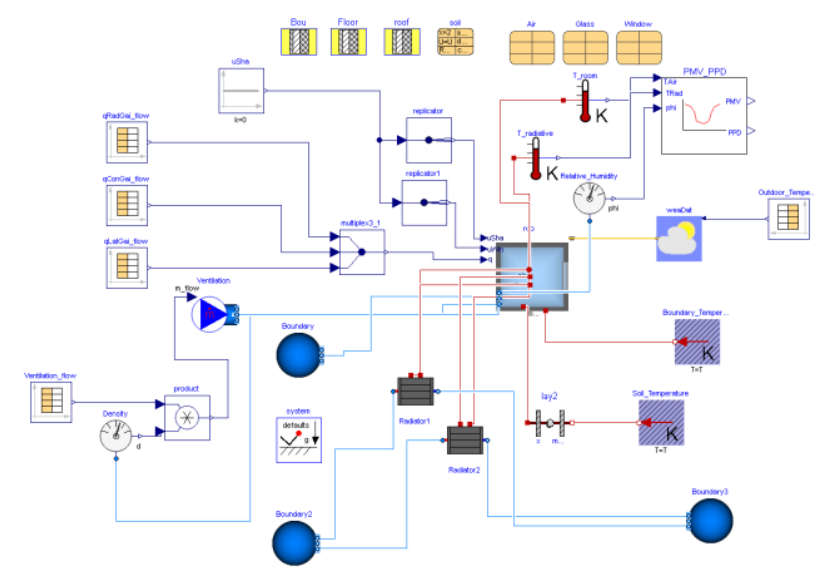

(b)

Figure 3 . Modelica model of the Foyer: (a) Block diagram of sub-models and (b) Global Dymola ${ }^{\circledR}$ model.

Ventilation, heating and internal gains: The mechanical ventilation system and the extraction system in the Foyer were implemented into our model using the MassflowSource T model of the Fluid package [16]. The model describes an ideal flow source generating prescribed values of mass flow rate and temperature. The prescribed mass flow rate and temperature of the ventilation systems were obtained from the building control centre and implemented into our model using the DaySchedule model. The heating system was modelled using the RadiatorEN442_2 model of the Fluid package. The model represents a radiator that can be used as a dynamic or steady-state model. Furthermore, this model uses two heat ports to represent room air and radiation temperatures to denote the convective and radiative heat flow between the radiator and the room. Dayschedule models were used to represent the occupancy profile in the Foyer. The models were connected to the inlet connector qGai flow of the MixedAir model to add the internal radiative, convective, and latent heat gains.

Thermal comfort model: The Fanger model of the Utilities package in the Modelica Buildings library was utilized to calculate the PMV and PPD values during simulation time. This model uses Equation (6) to calculate the clothing surface temperature. However, based on ISO 7730, ASHRAE and European standards $[5,17,18]$, Equation (2) must be used for the calculation of the clothing surface temperature. In this context, the component was modified and Equation (6) was replaced by Equation (2). The six parameters that are used to calculate PMV and PPD could be implemented to the model as constant values or using input connectors.

$$
\begin{aligned}
& T_{c l}=35.7-0.0275(M-W)-0.155 I_{c l}\{(M-W)- \\
& 3.05 \times 10^{-3}\left[5733-6.99(M-W)-P_{a}\right]-0.42[(M- \\
& W)-58.15]-1.7 \times 10^{-5} M\left(5867-P_{a}\right)-0.0014 M
\end{aligned}
$$

$\left.\left(34-T_{a}\right)\right\}$

\section{Results and discussion}

To validate our developed Modelica model, the predicted room temperature and relative humidity are compared with measured data. The Absolute Error (AE) is calculated to quantify the deviation between predicted and measured values. Figure 4 shows the discrepancies between the predicted results and the measured room temperature and relative humidity of the third cycle. The discrepancies averaged about $-0.25{ }^{\circ} \mathrm{C}$ for the room temperature and $1.1 \%$ for the relative humidity. However, the $\mathrm{AE}$ regarding the room temperature reached a maximum of $1.7^{\circ} \mathrm{C}$ during the presence of solar radiations and averaged about $0.4^{\circ} \mathrm{C}$ for the rest of the time. These results clarify the effect of solar radiation on both studied variables. Therefore, the predicted room temperature and relative humidity by the developed Modelica model have a good agreement with the measured data and the discrepancies were less than the uncertainty of the measurements (less than $0.4{ }^{\circ} \mathrm{C}$ for the air temperature and $3.0 \% \mathrm{RH}$ for the relative humidity) for the overwhelming majority of time as shown in Figure 4. However, during high solar radiations, the discrepancies were higher than the measurement uncertainty. It is suggested that the lack of solar radiation data on the experimentation day, which affects the room temperature due to the presence of the two glazed external walls, is the main reason behind the gaps between predicted and measured results during high solar radiation.

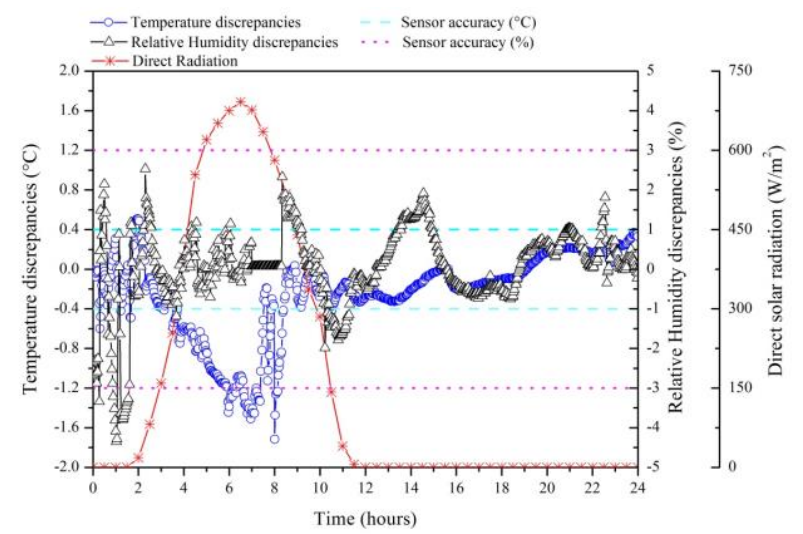

Figure 4. Discrepancies between the predicted and measured room temperature and relative humidity of the third cycle.

In order to deeply discuss, evaluate and compare predicted and measured results regarding the indoor thermal environment of the Foyer, The indoor thermal comfort indices (PMV-PPD) are calculated using the 
aforementioned equations. In the experimental work, these indices are calculated based on the experimental measurement data regarding the environmental parameter and the occupants' related parameters summarized in Table 3.

The average values of PMV and PPD obtained from both the experimental and the developed model for the five experimental cycles are presented in Figure 5. The results show a good agreement between simulation and calculated results based on measured data. In general, all the obtained average values of PMV are negative and fall outside the acceptable comfort range [$0.5,0.5]$, the obtained average values from the Modelica model of PMV and PPD averaged -1.2 and 33.69\% respectively. The average values have only $1 \%$ and $1.5 \%$ difference with the experimental averaged values of PMV and PPD. These results indicate that the indoor thermal environment of the Foyer is cold. Bearing in mind that average outside temperature has decreased gradually from $12^{\text {th }}$ to $14^{\text {th }}$ November, the measured PMV values indicate that the indoor environment of the Foyer has become colder, which is consistent with the outdoor temperature data.

Table 3. Human parameters for calculating PMV.

\begin{tabular}{ccc}
\hline Parameter & Description & Values \\
\hline$M$ & Standing & $1.2 \mathrm{met}$ \\
$I_{c l}$ & Typical winter clothing & $1 \mathrm{clo}$ \\
$W$ & No external work & $0 \mathrm{met}$ \\
\hline
\end{tabular}

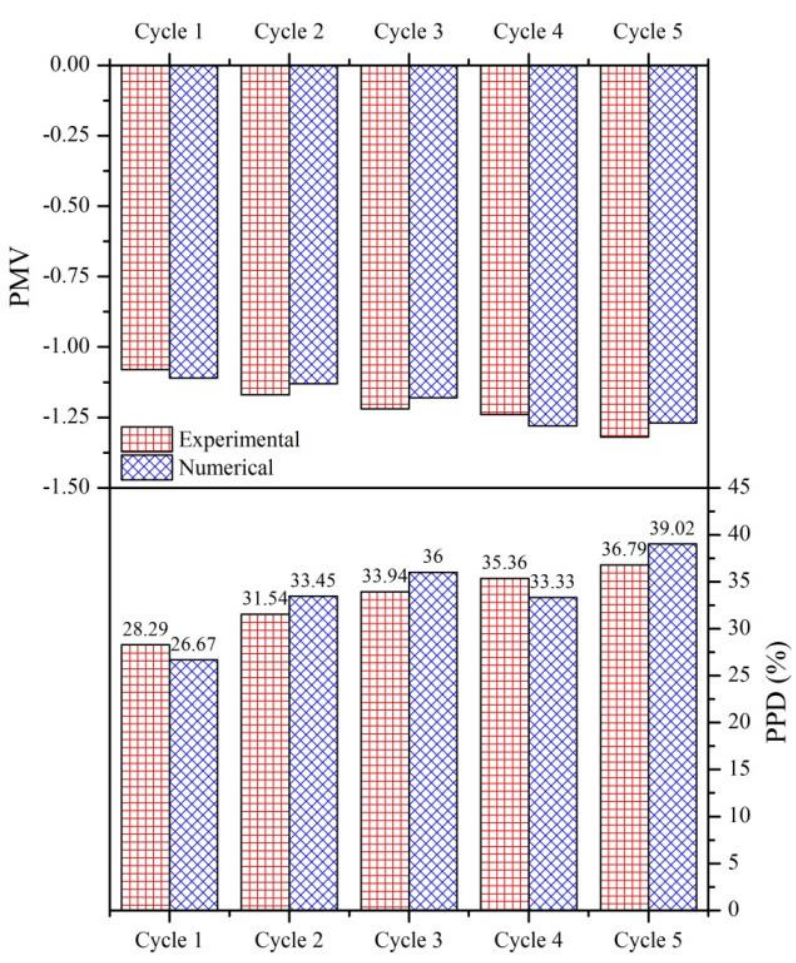

Figure 5. Average values of PMV and the corresponding PPD for the various cycles.
Lastly, all the obtained results indicate that the model prediction is in good agreement with the measured data, although some discrepancies were noticed. These discrepancies could be attributed to experimental errors which are a function of the accuracy of the sensor. In addition, the lack of exact occupancy profile at the time of experimentations and some weather data parameters, such as solar radiation and outside relative humidity could be the reason for much of the discrepancies observed at the beginning of the experimentation work and during the presence of intense direct solar radiations. These discrepancies can be reduced by monitoring occupancy profiles and matching simulation schedules with real data; however, this could result in increasing modelling time and complexity and outcomes robust results for specified periods. Bearing in mind that the main intention is to obtain a model that can represent the real building in general terms rather than out coming exact results for a specified time, the model is thus considered to be validated and deem it useful for further evaluations and investigations.

Furthermore, although the use of glass facades may ensure the maximum passage of solar radiation and thus reduce the heating demand during the heating season, they may cause discomfort to the occupants. In fact, regular changes in the outdoor climate affect the radiant temperature. For instance, intense solar radiation may lead to high mean radiant temperature values and low outdoor temperature with low solar radiation could lead to lowering the mean radiant temperature values, and since the mean radiant temperature has a major influence on occupants' thermal comfort, this leads to instabilities in the indoor thermal environmental conditions and thus inconsistent thermal comfort.

Based on the aforementioned discussion, we propose the use of an advanced control strategy, such as thermal comfort based control, for the regulation of heating system set-point. Such an approach aims to maintain consistent thermal comfort conditions rather than fixed indoor temperature. Besides, it takes into consideration the heat gain during high solar radiation to decrease the set-point temperature, thus leading to energy-savings.

\section{Conclusions}

In this study, the object-oriented modelling tool based on the Modelica approach was used to investigate the thermal behaviour and occupants' thermal comfort in a highly glazed room within the European context. The model was built by coupling the Modelica Standard Library with several packages of the Modelica Buildings Library. To validate the developed model, predicted results regarding room temperature, relative humidity, and thermal comfort indices were compared with measured data. The comparison indicated a good agreement between model predictions and measured data. Hence our developed model is considered to be validated. Furthermore, the results indicated that the two external glazed facades have an effective influence on the indoor thermal environment of the Foyer, either 
during high solar radiation or during low outdoor temperature. Thus, an adequate control strategy must be applied to the heating system in order to recuperate the heat loss during low outdoor temperature and to take into consideration the heat gain during high solar radiation. Finally, our next step is to use our validated model to apply a new control strategy based on the thermal comfort indices to investigate its influence on the indoor thermal environment and occupants' thermal comfort.

KEYWORDS: PMV, PPD, Object-Oriented approach, Indoor thermal environment, Thermal behaviour, Thermal comfort.

The authors would like to thank the Grand Est Region, France, and the European Regional Development Fund (FEDER) for funding this work.

\section{References}

[1] F. Belaïd, Untangling the complexity of the direct and indirect determinants of the residential energy consumption in France: Quantitative analysis using a structural equation modeling approach, Energy Policy. 110 (2017) 246-256. doi:10.1016/j.enpol.2017.08.027.

[2] European Parliament, Directive 2010/31/EU of the European Parliament and of the Council of 19 May 2010 on the energy performance of buildings, Off. J. Eur. Union. (2010) 13-35. doi:10.3000/17252555.L_2010.153.eng.

[3] ANSI/ASHRAE, Thermal Environmental Conditions for Human Occupancy Standard 552013, Ashrae. (2013). doi:ISSN 1041-2336.

[4] P.O. Fanger, Thermal comfort. Analysis and applications in environmental engineering., New York Mcgraw-Hill. (1972).

[5] ISO, ISO 7730: Ergonomics of the thermal environment Analytical determination and interpretation of thermal comfort using calculation of the PMV and PPD indices and local thermal comfort criteria, Management. 3 (2005) 605-615. doi:10.1016/j.soildyn.2004.11.005.

[6] M. Taleghani, M. Tenpierik, S. Kurvers, A. Van Den Dobbelsteen, A review into thermal comfort in buildings, Renew. Sustain. Energy Rev. 26 (2013) 201-215. doi:10.1016/j.rser.2013.05.050.

[7] J. Van Hoof, Forty years of Fanger's model of thermal comfort: Comfort for all?, Indoor Air. 18 (2008) 182-201. doi:10.1111/j.16000668.2007.00516.x.

[8] N.M. Mateus, A. Pinto, G.C. Da Graça, Validation of EnergyPlus thermal simulation of a double skin naturally and mechanically ventilated test cell, Energy Build. (2014). doi:10.1016/j.enbuild.2014.02.043.

[9] S.E. Ouldboukhitine, R. Belarbi, D.J. Sailor,
Experimental and numerical investigation of urban street canyons to evaluate the impact of green roof inside and outside buildings, Appl. Energy.

(2014).

doi:10.1016/j.apenergy.2013.09.073.

[10] S. Bontemps, L. Mora, Holzkirchen house modelling using modelica buildings library and comparison with measurments, in: 14th Conf. Int. Build. Perform. Simul. Assoc., Hyderabad, India, n.d.

[11] P.O. Fanger, Thermal comfort: Analysis and applications in environmental engineering, 1970.

[12] MEDDE, Réglementation thermique 2012: un saut énergétique pour les bâtiments neufs, 2011.

[13] W. Makondo, A. Merabtine, S. Pincemin, J. Podlecki, R. Garcia, Capteur multifonctions pour 1 ' évaluation du confort thermique dans les bâtiments, in: Congrès Fr. Therm., La Rochelle, France, 2015.

[14] M. Wetter, W. Zuo, T.S. Nouidui, Modeling of Heat Transfer in Rooms in the Modelica "Buildings" Library, Proc. Build. Simul. 2011 12th Conf. Int. Build. Perform. Simul. Assoc. (2011) 1096-1103.

[15] M. Wetter, W. Zuo, T.S. Nouidui, X. Pang, Modelica Buildings library, J. Build. Perform. Simul. $\quad 7 \quad$ (2014) 253-270. doi:10.1080/19401493.2013.765506.

[16] M. Wetter, W. Zuo, T.S. Nouidui, Recent Developments of the Modelica "Buildings" Library for Building Energy and Control Systems, in: Model. Conf., 2011: pp. 266-275. doi:10.3384/ecp11063266.

[17] ASHRAE, ASHRAE Standard 55-2013 Thermal Environmental Conditions for Human Occupancy, 2013. doi:ISSN 1041-2336.

[18] Cen, EN 15251: Indoor environmental input parameters for design and assessment of energy performance of buildings- addressing indoor air quality, thermal environment, lighting and acoustics, Eur. Comm. Stand. 3 (2007) 1-52. doi:10.1520/E2019-03R13.Copyright. 